\title{
Paradox Of Identities, Girls As Wives, Boys As Children: The Attitude Of In-School Female Adolescents In Enugu State Towards Early Marriages In Nigeria
}

\author{
Ursula Chigozie Nnabueze \\ Department Of Health And Physical Education, \\ Enugu State University Of Science And Technology (ESUT) Enugu State, Nigeria.
}

\begin{abstract}
Adolescence is a critical transitional period of physical, emotional and psychological changes. It is a very critical period of self-identity formation, but some traditional/cultural practices complicate and confuse the girl child as to who she really is. Is she a girl child or a woman already? This leads to the perception of a girl today, a woman the next day because the girl child could be married off within the blink of an eye. Early marriage, also known as child/forced marriage, is among the Harmful Traditional Practices (HTPs) still perpetrated in some parts of Nigeria today. HTPs are forms of violence which are committed primarily against girls and women in certain communities for so long that they are considered or presented by perpetrators as part of acceptable cultural practices - the most common being forced/early marriage. Popular discussions tend to focus attention on early marriage in Muslim communities of Northern Nigeria. However, some studies have reported that early marriage also occurs in some Muslim (Western) and Christian (Eastern) communities of Southern Nigeria. Ironically, boys are treated as boys while girls are treated as marriageable women. A cross sectional survey research design was adopted for the study. The population comprised of 27,831 female secondary school students from the all-girls 35 secondary schools in Enugu Education Zone, Enugu state, Nigeria. The multi-stage sampling procedure was adopted to select the sample size of 320 girls from four schools. The instrument for data collection was a structured questionnaire titled Attitude of Adolescents toward Early Marriages (AATEM). The questionnaire was validated by three experts and a reliability index of. 81 was obtained. Data analysis performed using simple percentages showed that a great percentage of these girls have negative attitude towards early marriages. The study recommended that government and other social institutions must guarantee girls' access to basic education and find new ways to enable families enroll girls in school, encourage them to stay in school, and thereby delay premature marriages.
\end{abstract}

KEYWORDS: Adolescents, Identity, Early Marriage, Child Marriage Harmful Traditional Practices. 

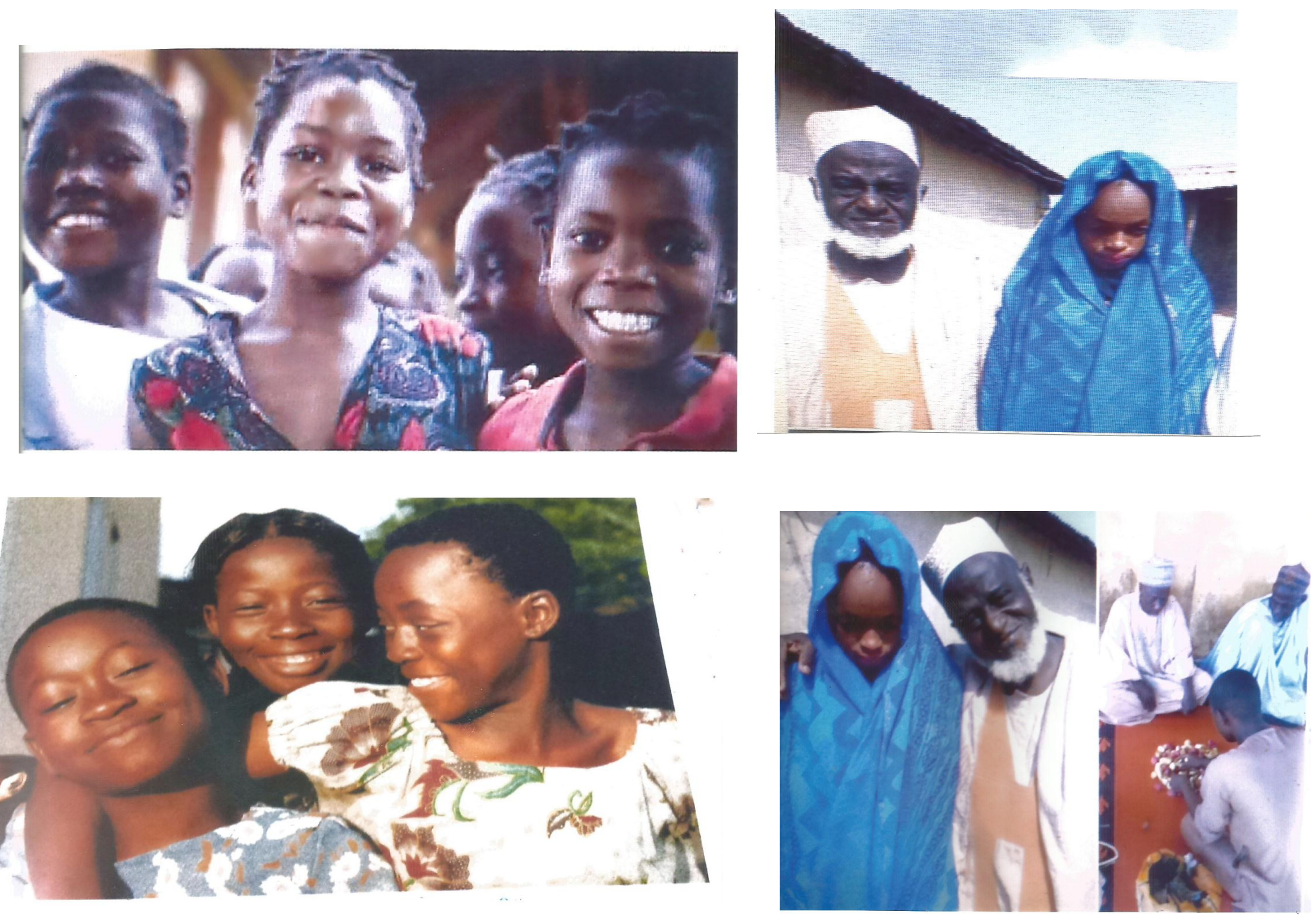

INTRODUCTION

Child marriage, which has existed for centuries is a complex issue, rooted deeply in tradition, culture, poverty, religion, gender inequality, discrimination and low value placed on the girl child. Despite the fact that 158 countries have set the legal age of marrying at 18 years, laws are rarely enforced since the practice of marriage of young children is upheld by tradition and social norms (United Nations Populations Fund, UNFPA, 2017). Traditional practices usually reflect values and beliefs held by members of a social group or community. While some traditions may be beneficial to the whole members, others are harmful to specific groups such as women, girls, and albinos among others.

Traditionally, women and girls lack autonomy because generally they are under considerable inhibition even in issues concerning their lifestyle, health, sexuality and fertility control. These inhibitors are called Harmful Tradition Practices (HTPs). HTPs have been used over the centuries, as weapons to deny women and girls their rights to freedom of expression and to attain the highest standard of health and opportunities (Chukwukere, 1998).

In most part of Nigeria, traditional practices are deeply anchored on the Patriarchal system where culture is supreme and uncompromising because of its complex phenomena with distinctive spiritual, material, intellectual and emotional features (Mbagwu, 2009). Patriarchal culture subjugates women and girls and render them vulnerable to HTPs as: 
- exclusion of women from discussion and sharing of lands;

- women obtaining permission from their husbands before accepting or adopting any contraceptive method;

- girls and women undergoing Female Genital Mutilation/Cutting FGM;

- son preference

- widowhood rites and

- Early/child/forced marriage for teenage girls.

United Nations Children Fund, UNICEF (2014) described early/child/forced marriage as a union in which children are given out in matrimony before marriageable age of 18 years. Therefore, this study considers child marriage as marriage engaged in before the age of 18 years - when the girl is physically, physiologically and psychologically not ready to shoulder the responsibilities of such a union. These early marriages are often characterized by:

- the girl's childhood cut short;

- her fundamental rights compromised;

- she has no choice about the timing of the marriage;

- too young to make any enforced decision about the implications of the marriage itself;

- decision to marry made by others and

- usually married to older man enough to be their father or even grandfather.

World Health Organization, WHO (2013) reported that more than 700 million women alive today were married before their $18^{\text {th }}$ birthday, equivalent of 10 percent of the world's population. It's worthy to note that child marriages vary both within and between countries. UNICEF (2014) posited that the ten countries with the highest rates of child marriage are: Niger, Chad, Central African Republic, Bangladesh, Guinea, Mozambique, Mali, Burkina Faso, South Sudan and Malawi.

Fig 1: Ten countries with the highest rate of child marriage

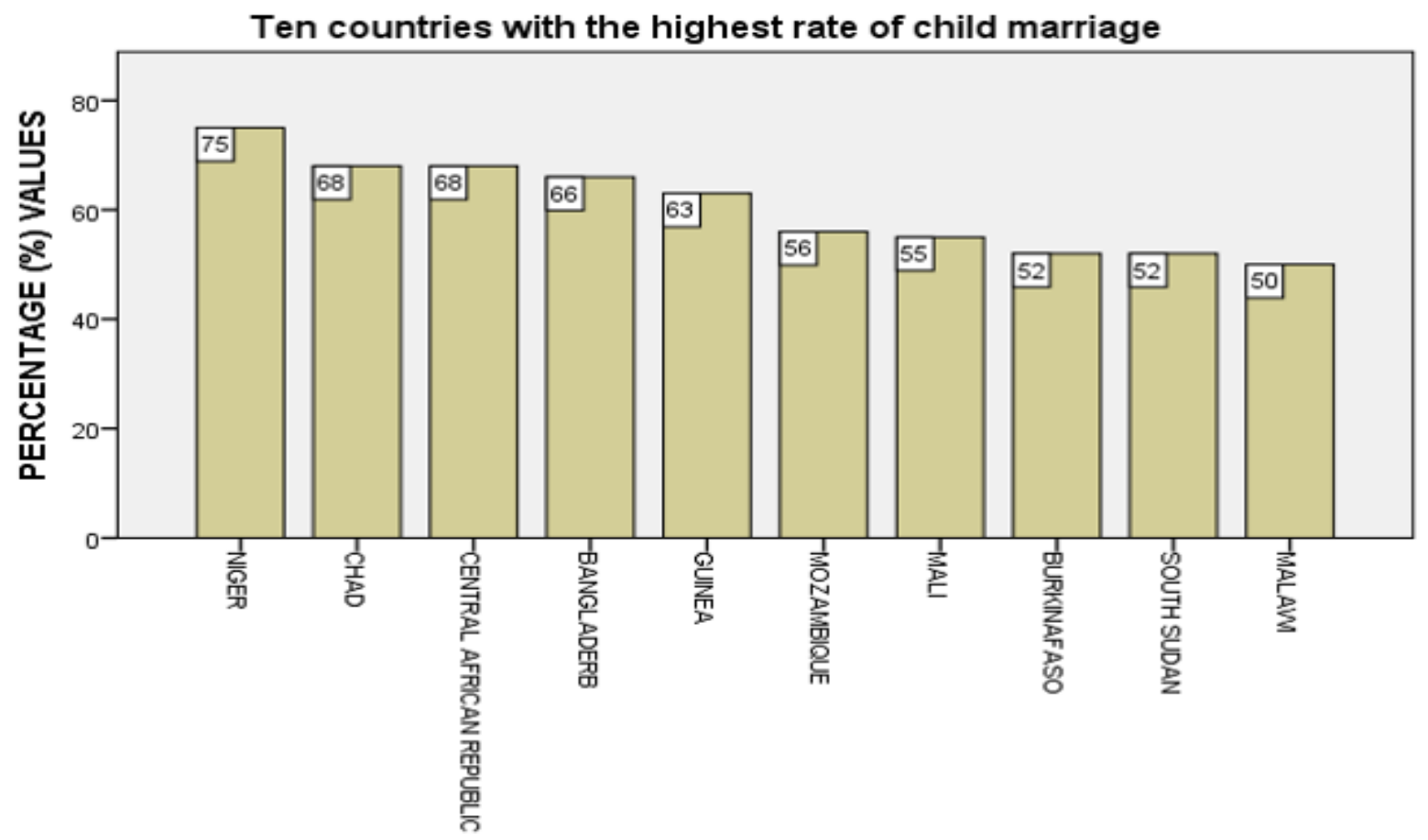

COUNTRIES

Source: UNICEF 2014 
Early marriage is epidemic in Sub-Saharan African (particularly Niger, Mail, Chad, Kenya, and Nigeria) and many other parts of the developing world such as South Asia (Adekola, Akanbi \& Olawole 2016). UNFPA/UNICEF (2017) reported that South Asia is currently leading the way to reducing child marriage. This means that the global burden of child marriage is shifting to Sub-Saharan Africa.

\section{Let Female Children be Children and Not Brides}

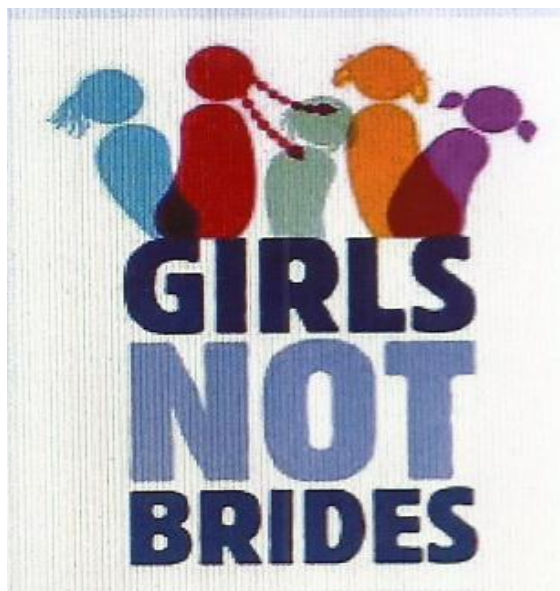

Adolescence is a critical transitional period of physical, emotional, Psychological and social changes (UNICEF, 2013). It is a very critical period of self-identity formation but some cultural practices complicates and confuses the girl child as to who she really is - a girl or a woman. The result is the consequent perception of being a girl today, then a woman tomorrow because girls could be married off at a very short notice. It is common to find girls who marry at age 11 or 12 in some traditional societies in Africa but very uncommon for boys. Bledsoe and Cohen (1999) stated that in many of these areas, girls from 11-16 years are considered matured enough to be wives (female fecundity equals to a wedding) while very few African societies consider boys of 15-19 years matured enough for the responsibilities of husband hood/fatherhood. The above scenarios by implication define girls of 11-16 years as adults and boys of 11-16 years as children/teenagers. The curious question is why is this so?

WHO (2013) stated that many societies prize virginity for girls (not for boys) before marriage and this manifests in early marriage designed to prevent the girl child from unsanctioned sexual activity, which they view as defying and undermining their community's religious and cultural norms. Other reasons include:

- poverty, to reduce the number of children to feed and educate;

- collection of huge bride prize (cash, cattle, land and other valuables) from the prospective suitors;

- belief that sexual intercourse with a virgin cures HIV/AIDS;

- protect young girls from sexual attacks and violence;

- ensure young girls do not become pregnant before wedlock thereby bringing shame and dishonor to her family;

- marrying girls off before puberty brings blessing on their families.

No social, cultural or religious rationale for child marriage can possibility justify the damage these marriages do to the young girls and their future potentials. 


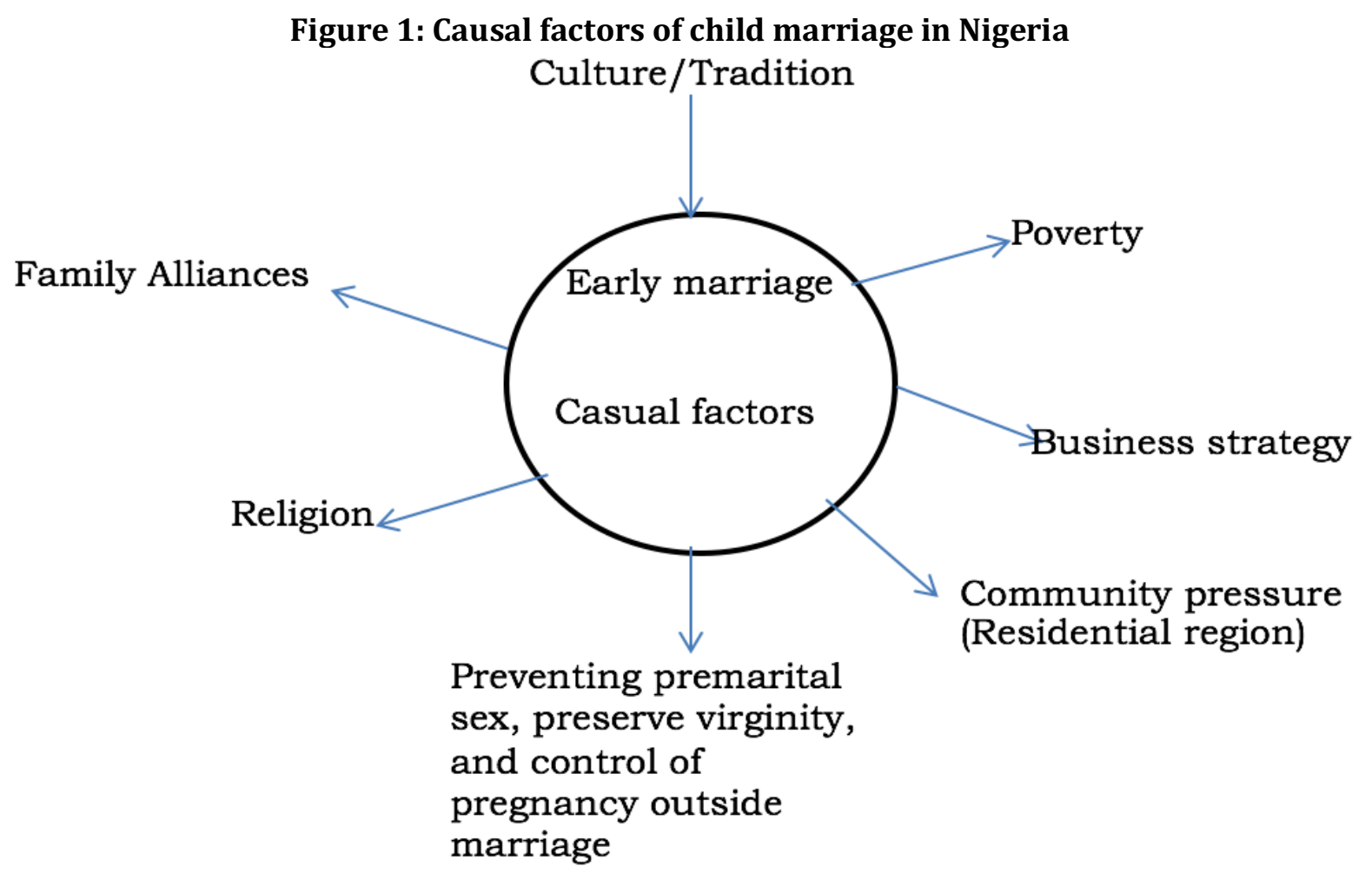

Source: Adekola, Akanbi and Olawole 2016.

\section{Turning Young Girls into Murderers and Wanderers.}

Times have changed, several decades ago young girls dutifully accepted child/ early/forced marriages as dictated by their parents and society. Nowadays, with the advent of television, radio, internet and other social media platforms some of these young girls no longer obey their parents, religion and society in the case of early/forced/child marriages. There have been reported cases of absconding and missing girls who ran away from such marriages.

Still fresh in mind is the case of a 14 year old girl in Northern Nigeria, who went to the extent of poisoning her so called husband and two of his friends by serving them an evening meal laced with rat poison. This is just the tip of the iceberg as some of these cases do not come to public knowledge in Nigeria because of the culture of silence surrounding cultural/religious issues as HTPs.

Obiweluozo (2018) reported that because of the wide age difference between them and their elderly husband, and inability to cope with the sexual demands from these spouses who are as old as the girls' fathers and grandfathers, some of these child brides run away to commercial cities to become sex hawkers. They also become easy preys for ritualists, human traffickers, pedophiles and sex pimps. Some have even gone as far as attempting suicide should their attempts to run away fails. While some have been hacked to death by their husband when their attempt to run away failed. 


\section{Children giving birth to Children}

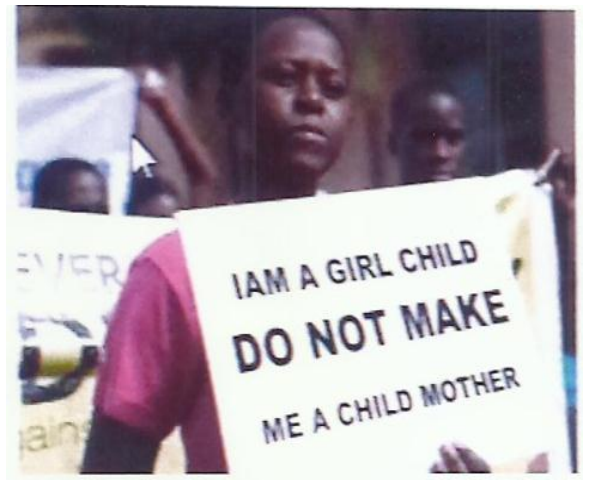

UNICEF (2014) decried that girls, aged 15-19 years are giving birth to up to 15 million babies a year. Girl child married off to an older man starts experiencing sudden unwanted, traumatic, painful sexual relationship. Automatically, she starts bearing children while still not yet biologically, physiologically and psychologically mature. Obianyo (2000) stated that childbirth may result in the death of the child bride. Some other pregnancy related complications like pelvic disproportion and dislocation resulting from incompatibility of the fetus and the immature pelvic bones, extensive laceration of the reproductive organs, the perineum and fistulas (urethral, vagina or recto-vagina) may occur.

UNICEF (2014) reported that complication of pregnancy and childbirth are the leading causes of death in young girls 15-19 years in the developing world. Early pregnancy and difficult childbirth exposes the baby to complications of premature birth. Still birth and newborn deaths are 50 percent higher among mothers under the age of 20 than in women who got pregnant in their 20s. Women marrying later or have delayed pregnancy beyond their adolescence have more chances of staying healthy, have better education and thereby, the opportunity to build a better life for themselves, their families and communities. Early marriage and childbirth are intrinsically linked to low levels of education, high levels of violence and abuse, social isolation (playing with peers today, married off to a total stranger tomorrow).The power dynamics of HTPs, resulting in increased gender inequality, perpetuation of cyclical inter-generational poverty, threatens the well being of future generations, families and society. These factors negatively impacts on the possibility of achieving the Sustainable Development Goals (SDGs).

\section{Her-story not His-story (History)}

UNFPA (2013) warned that if early marriages were not properly addressed, the United Nations (UN) Millennium Development Goals (MDGs (4 and 5-calling for a two - third reduction in the under five mortality rate and a three- fourths reduction in the maternal deaths will not be met by 2015 and so it turned out to be. Now the global community under the UN is unto the SDGs 2030, which is a plan of action for people, planet and prosperity built on the principal of leaving no one behind, with goal number 5 being the achievement of gender equality and empower all women and girls. Its target 5.3 is the elimination of all harmful practices such as child, early and forced marriages, and female genital mutilation among others (UN, 2014). Let's believe that, the global community will not leave the girl child behind this time around to child/early/forced marriages. Carrying the girl child along in this SDGs vision will enable her to exercise her human rights of writing her-story and not his-story (history).

\section{Early Marriage Violation of the Girl Child's Human Rights}

Universal Declaration on Human Rights (UDHR, 1948) stated vividly in the first two parts of Article 16 that:

- Men and women of full age without any limitation due to race nationality or religion have the right to marry and to found a family. They are entitled to equal rights as to marriage and at its dissolution.

- Marriage should be entered into only with the free and full consent of the intending spouses. 
International Centre for Research on Women, ICRW (2007) and Centre for Reproductive and Policies, CRLP (2011) stressed that the right to "free and full" consent to a marriage cannot indeed be "free and full" when one party is not sufficiently mature to make an informed decision about a life partner. Article 1 of the Convention of the Right of the Child (of which Nigeria ratified) states that a girl must have reached her $18^{\text {th }}$ birthday before entering into marital union. Also, there must be free and full consent of the choice and timing of her marriage.

Early marriage is recognized as a violation of the rights of the girl child because:

- it effectively ends her education;

- it blocks any opportunity to gain vocational and life skills;

- it exposes the child bride to the risk of too early pregnancy, child bearing and motherhood and

- increase her risk of intimate partner sexual violence, STIs and HIV among others (UNFPA, 2017).

Nigeria is signatory to some important international treaties and covenants against child/early/forced marriages such as:

- Convention on the Elimination of all forms of Discriminating Against Women and Girls (CEDAW, 1979);

- United Nations Convention other Right of the Child (CRC, 1989);

- International Conference on Population and Development (ICPD, 1994); and

- Fourth World Conference on Women (FWCN, 1995) among others.

Despite all these treaties and covenants ratified/signed by the Nigerian government early marriages are still being conducted against the girl child in Nigeria. The Nigerian government has the singular responsibility and obligations of making sure that these young girls' rights are respected and protected.

\section{Early Marriage: The Nigeria Scenario.}

The Nigerian society is predominantly characterized by a patriarchal and patrilineal social system with beliefs and norms legitimizing and perpetuating unequal treatment towards girls and women (Akpala, 2003). Some families still see the education of the girl child as a bad investment as she is expected to get married into another family unlike the boys. Kwarai (2011) asserted that this socio-cultural perception is very strong in the North East and North West with the highest number of girl children not enrolled in school or dropout out of school to get married. Population Council (2014) decried that these girls are denied the proven benefits of education, which include improved health, lower fertility and increased economic productivity.

Nationwide 20 percent of girls get married by age 15 and 40 percent by age 18 . Population Council (2014) asserted that Northern Nigeria has some of the highest rates of early marriage in the world, with the North Western region having 48 percent of girls married by age 15, 78 percent by age 18 , and 27 percent of these married girls are in polygamous marriages. 
Table 1: Age of child marriage by location in Nigeria 2008

\begin{tabular}{|l|c|c|c|}
\hline & No of observation & \multicolumn{2}{c|}{ Age of first marriage } \\
\hline Area of residence & \multicolumn{3}{|c|}{ Mean } \\
\hline Rural & 20,153 & 16 & 17.1 \\
\hline Urban & 9,277 & 16 & 19.1 \\
\hline Region & \multicolumn{3}{|c|}{} \\
\hline North Central & 5,630 & 17 & 18 \\
\hline North East & 5,467 & 15 & 15.8 \\
\hline North West & 6,582 & 15 & 15.4 \\
\hline South East & 3,201 & 20 & 21.0 \\
\hline South West & 4,184 & 19 & 19.5 \\
\hline South South & 4,366 & 20 & 20.7 \\
\hline
\end{tabular}

Source: Adekola, Akanbi and Olawole 2016

The table speaks for itself as girls from Northern Nigeria are likely to marry by age 15 , thereby making them dependent on their husbands for life without any educational and entrepreneurship skills while those in the South marry by age 20. Lending their voices to this discourse, Annabel and Mairo (2007) stated that early marriage is most endemic in the Northern part of Nigeria with 45 percent of teenage marriages. Girls in Northern Nigeria marry at an average of five years earlier than their counterparts anywhere in Southern Nigeria. Some studies have also reported on incidences of child marriage in Southern Nigeria. Mbagwu (2009) reported early marriage as one of the foremost HTPs that take place in Ebonyi state, Eastern Nigeria. While Adebambo (2010) stated that girls from Sabo area (residential area where people from Northern Nigeria live in Ogun State) do go into early marriage because of pressure from their community. (Ofujeme 2010 in Obiweluozo 2018) on socio-demographic correlates of early marriage in Ayamelum Local Government Area, Anambra State, stated that 83 percent of early marriages that occur there were contracted for the girls by their parents. In addition (Umaru, Lorapuu, Osagie, Okoh \& Zoakah 2016 in Obiweluozo 2018) reported that in Plateau State, central region of Nigeria, most girls are forced into marriages because of poverty and poor educational level of their parents.

Based on this scenario, the Child Rights Acts was passed in 2003 raising the minimum age of marriage to 18 for girls. However, Federal laws may be implemented differently at the State level and to date, only a few of the 36 states in Nigeria have begun developing provisions to execute this law (Akpala, 2003). To further complicate matters, Nigeria has three different legal systems operating simultaneously- civil, customary and Islamic. The State and Federal governments have control only over marriages that take place within the civil system.

\section{Problem Statement}

Nigeria ranks $13^{\text {th }}$ among 20 Countries with the highest rate of child marriages of which 16 of them are African countries (nationonline.net nd). Quite a good number of studies both international and national have reported that early child marriage results to spiral intergenerational consequences. Cyclical acute poverty, physiological and psychological ill health, maternal and in fact mortality and morbidity, illiteracy, isolation, suicide, sexual violence among others (Nour, 2009). Onyido and Brambaifa (2018) asserted that early child marriage is predominant in the Northern part of Nigeria where North West and North East geopolitical zones account for over $45 \%$ of child marriages as well as the highest levels of illiteracy amongst females in Nigeria. This does not mean that there are no cases of early child marriages in the Southern part of Nigeria. 
These cases continue to occur inspite of the Nigerian constitution frowning at early child marriages. The Federal Laws and the Nigerian Constitution 1999 prohibit early marriage of either gender before 18 years. (Okafor, 2014). The Federal Ministry of Women Affairs and Social Development (2016) reported that the Nigeria Government has moved a National Strategy to end child Marriage in Nigeria (2016-2021). While Osibanjo, Vice President (2016) stated that the Nigerian Government has taken firm step to stop child marriage by 2030.

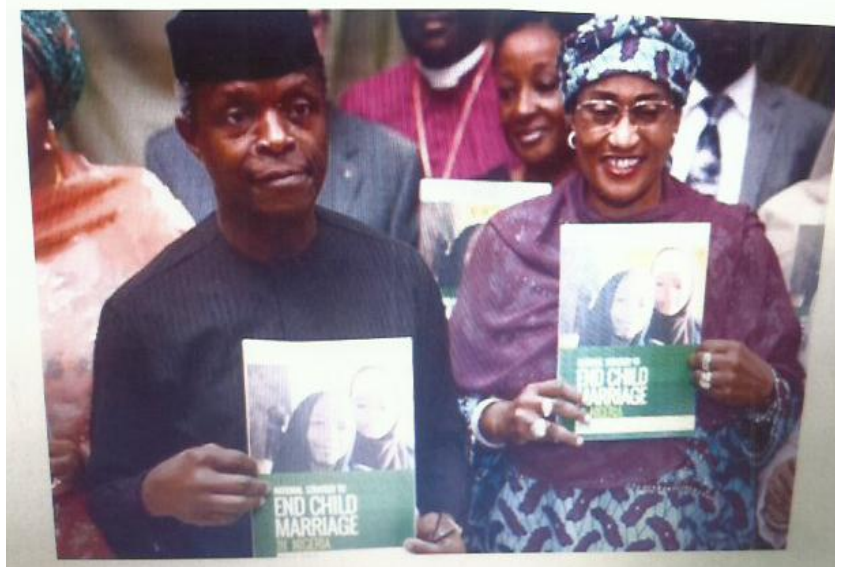

Despite all these moves by the Nigerian Government to stop early child marriages, cases of it are still been reported. Four recent reported cases of early marriages prompted this study: in 2014 Wasila Umaru 14 year old child bride poisoned her 35 year old husband and his two friends by lacing the evening meal she served them with rat poison; Alhaji Ahmed Bakura, Former Governor of Zamfara State and Ese Oruru of Bayelsa State were also reported to have been involved with child marriages (Onyido \& Brambaifa 2018); and by December $10^{\text {th }} 2018$, the Social Media and Face Book was washed with the pictures of a 70 year old man marrying a 15 year old girl in Laipai, Minna, Niger State (Naija.com > legit 2018). These cases are just the tip of the ice berg considering the culture of silence that surrounds issues of HTPs.

Enugu State may not be in the lime light as regards to early child marriages in Nigeria but that does not mean that pocket cases of early child marriages do not occur in Enugu State. There have been reported cases of child marriages in neighboring states (Ebonyi, Abia, Imo and Anambra States) that have same language and cultural practices with Enugu State. Based on the above premise the researcher decided to add to the already existing pool of knowledge in this area by finding out the attitude of in-school female adolescents in Enugu State on early child marriages in Nigeria.

\section{Research Framework}

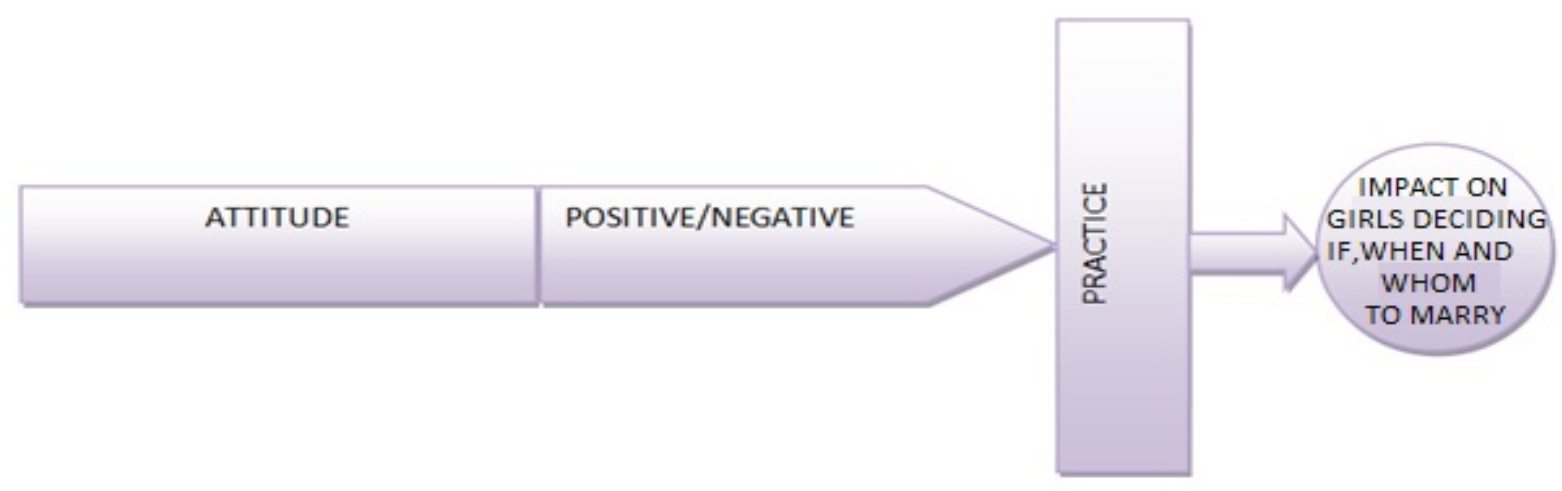

METHODOLOGY

A cross sectional survey research design was adopted for the study. The population comprised of 27,831 female secondary school students from the 35 all girls' secondary schools in Enugu Education zone, Enugu State, Nigeria (Post-Primary School Management Board, PPSMB 2018). The multi stage sampling procedure was adopted to select the sample size of 320 female secondary school students from four secondary schools in Enugu Education zone. The instrument for data collection was a structured questionnaire titled Attitude of in-school 
female Adolescent towards Early Marriage (ASFAEM). ASFAEM had four response options of Strongly Agree (SA), Agree (A), Disagree (D) and Strongly Disagree (SD) during data analysis SA and A were pulled together to mean positive. While D and SD were pulled together to mean Negative. The instrument was validated by three experts and a reliability index of. 81 was obtained using Cronbach Alpha. Data analysis was performed using simple percentages.

\section{Research Highlights}

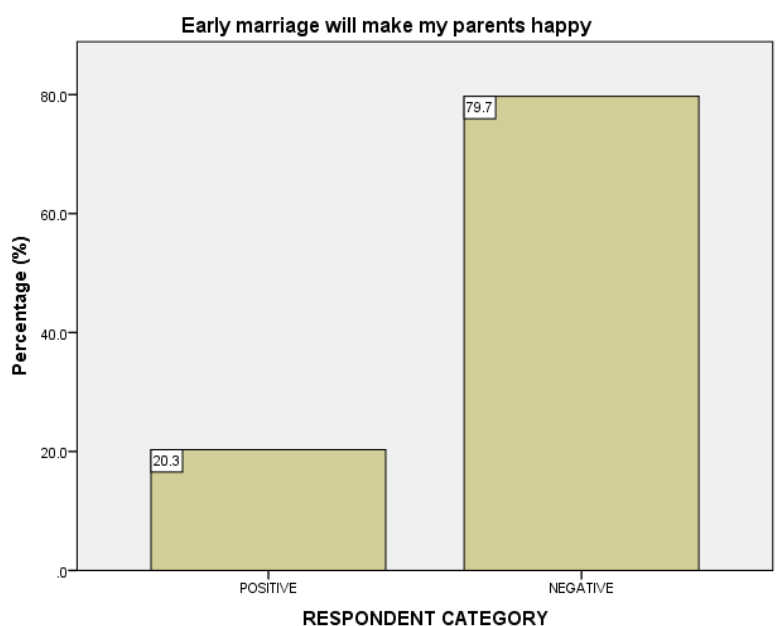

Majority of these girls, $97 \%$ feel that their getting married early will not make their parents happy. This is quite plausible because among the Igbos of Eastern Nigeria giving their children a good Western education is one of the major aspirations of every parent. It's no secret that early marriage cuts short girls education.

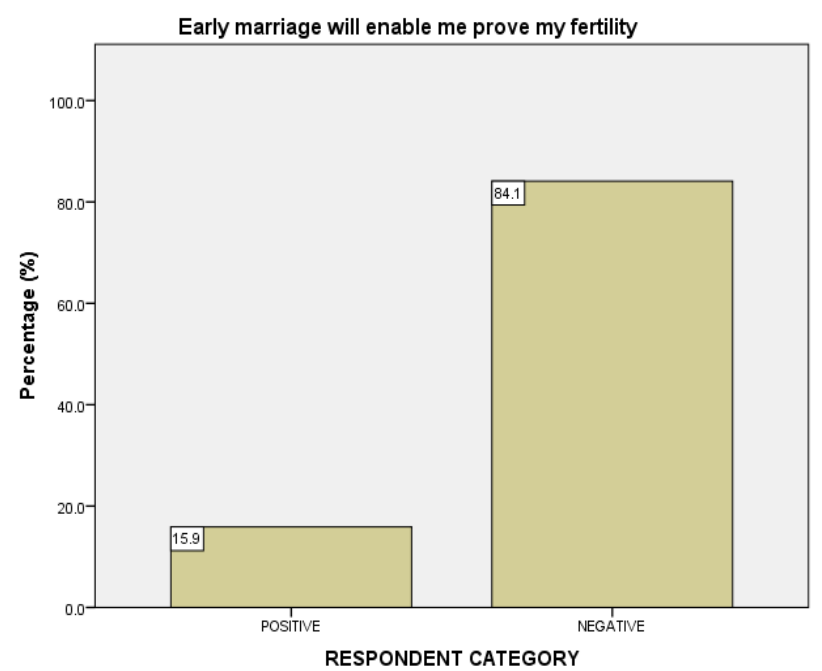

Eighty four percent $(84 \%)$ of these girls stated that they do not feel early marriage is necessary for them to prove their fertility. This notion could be as a result of the fact that most young people are experiencing early sexual debut for some obvious reasons - internet access with all sorts of sexual information, television, movies, porn films, magazines, and novels among others. After all, some research reports are coming up with high incidences of teenage pregnancies and unsafe abortions among young girls.

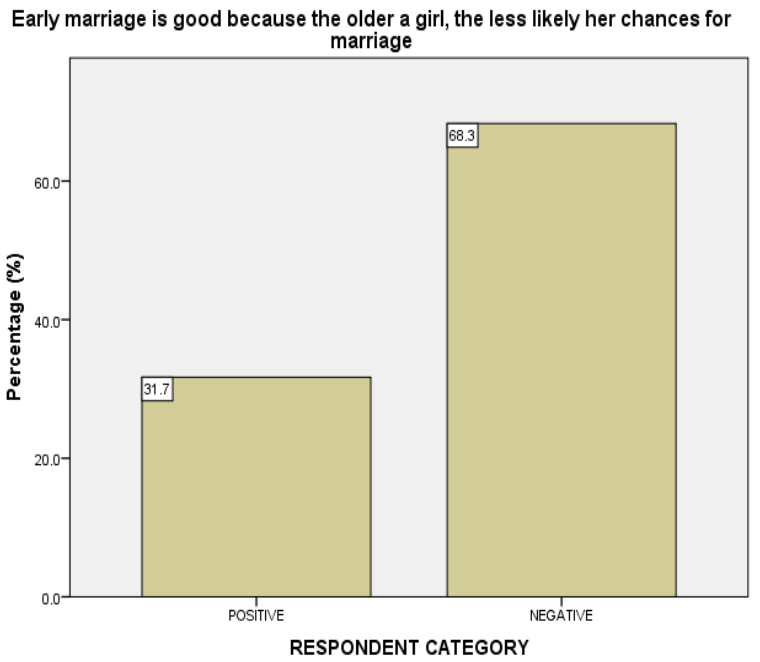

Surprisingly almost a third of these in-school girls $31 \%$ indicated that early marriage is good because the older a girl, the less likely her chances for marriage. This condoning attitude towards early marriage exhibited by these young girls could be pinned to the Igbo culture that looks at marriage as the ultimate achievement of any young girl/woman. Also fueling this attitude is the Igbo societal teaching that the older a girl gets the less chances of her getting a marriage partner. This societal attitude/disposition is buttressed by this saying "Oge Nwanyi na agafe agafe," meaning that a girl's/woman's marriageability passes with time. Unlike boys who are socialized to believe that they are eligible for marriage no matter their age.

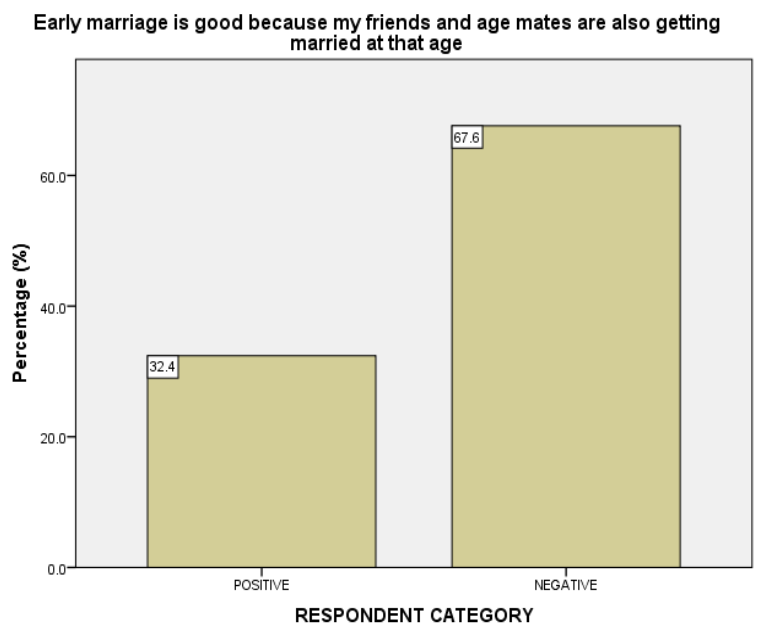

Around $32 \%$ of these school girls felt that early marriage is good because some of their friends are getting married. This is not a surprising response as some of them might be feeling left behind or not measuring up to societal expectations by getting married early 


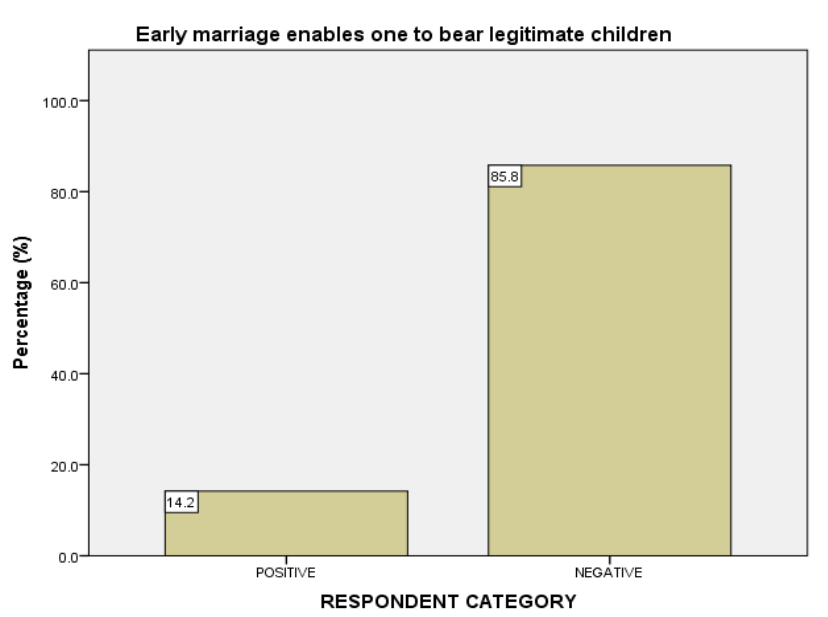

On early marriage will enable one bear legitimate children, $85 \%$ of these in-school girls felt that's true. This disposition of the respondents could be alluded to the fact that the Igbo culture frowns heavily on girls having children outside wedlock. Though, same aversion is not extended towards boys. For the boys, it's kind of pardonable but for the girls, it's kind of a stigma for life. No man within the Igbo culture would want to marry the girl. This kind of societal attitudes may be one of the drivers of the rise of the current pop culture of "baby mama and baby daddy syndrome" among young people not minding societal expectations.

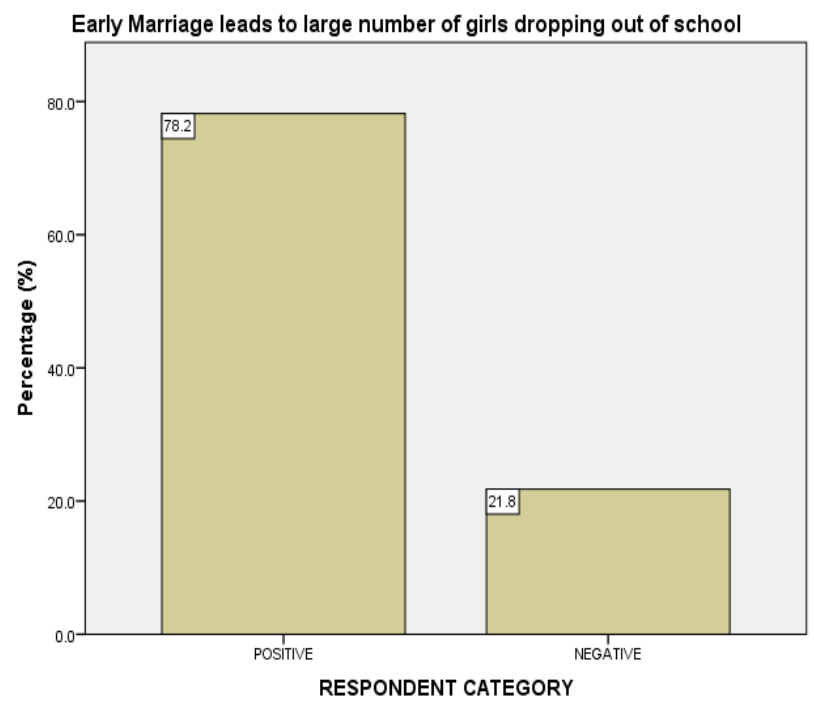

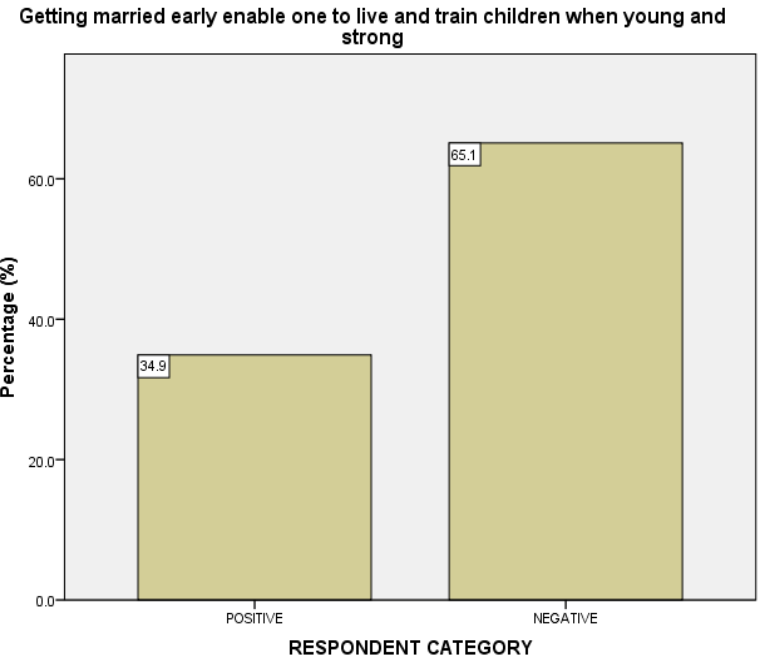

One third of the girls $35 \%$ felt that early marriage will enable a girl train her children while she's still young and strong. They failed to understand that a young married girl may not have what it takes to bring up children successfully- financial, psychological, and biological maturity.

Most of the respondents $78 \%$ felt that early marriage leads to girls dropping out of school and this has been widely reported by some researchers as one of the serious downside of early child marriage. The Igbo culture fixation on marriage especially for the girls makes some parent to barely have patience for their daughter to finish secondary and they will start insinuating they should get married before they are too old for marriage. Some people even go as far as insinuating that once a young girl enters for university education, her chances of getting suitors for marriage narrows drastically. 


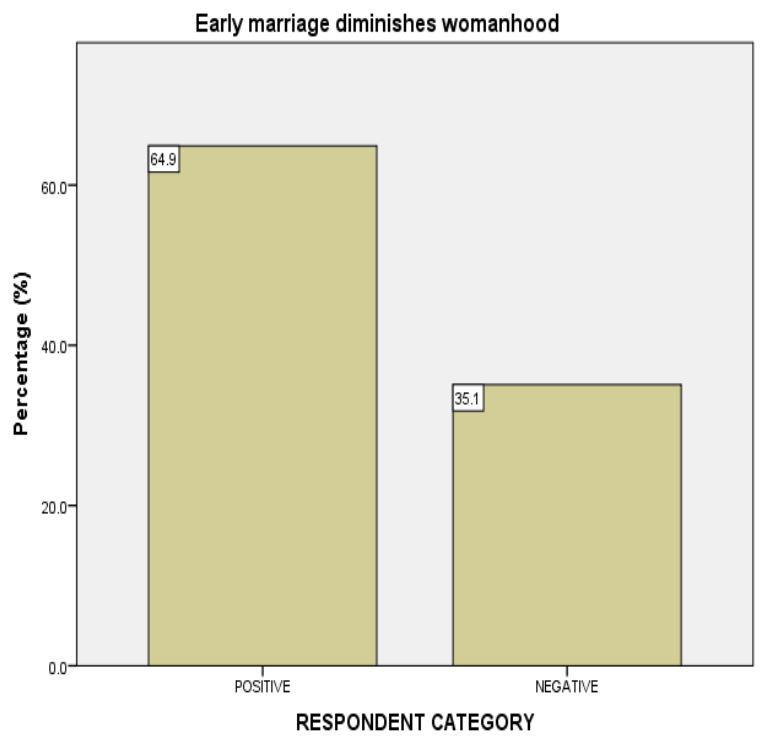

Almost $35 \%$ of these girls do not feel that early marriage diminishes womanhood. This is a very regrettable attitude toward a detestable developmental and health issue as early/child marriage. This condoning attitude expressed by these girls is not surprising because, they have been socialized into thinking that marriage is the ultimate achievement for any girl/woman.

\section{Early marriage leads to early pregnancy which can result to maternal mortality and infant mortality}

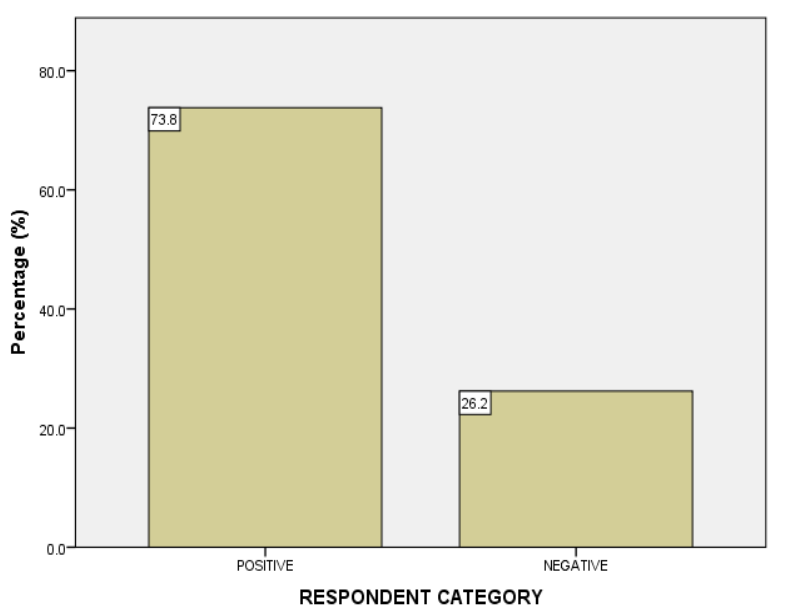

On early marriage leading to high maternal mortality and morbidity rate, $73 \%$ felt that it's so true. This affirmation is in line with reports from some researchers, who posited that due to the anatomical and physiological immaturity of young girls below 18 years, their bodies cannot handle pregnancies successfully without terrible consequences.

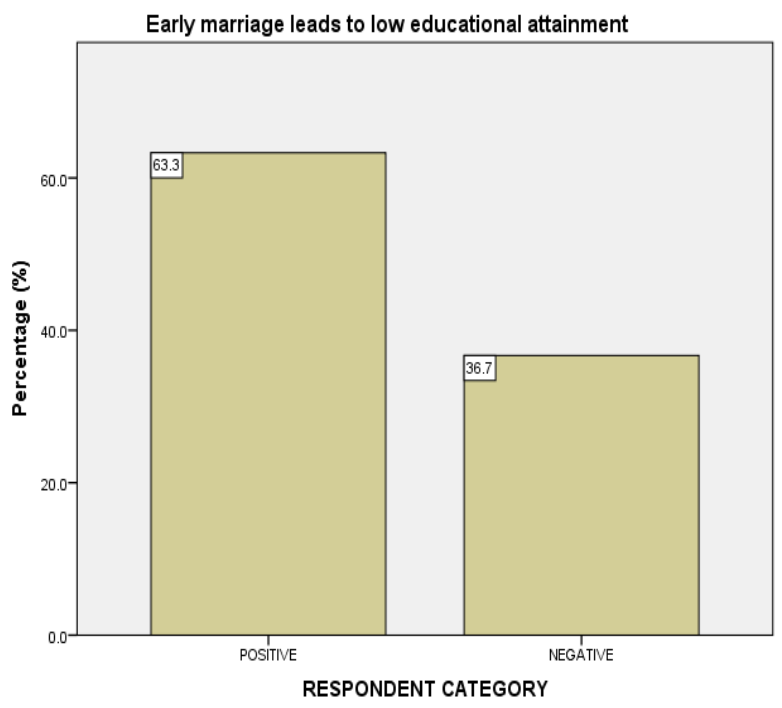

Around $36 \%$ of these girls stated that early marriage does not lead to low educational attainment, which is surprising and contradicting to where $78 \%$ of them earlier stated that early marriage leads to school drop out for young girls.

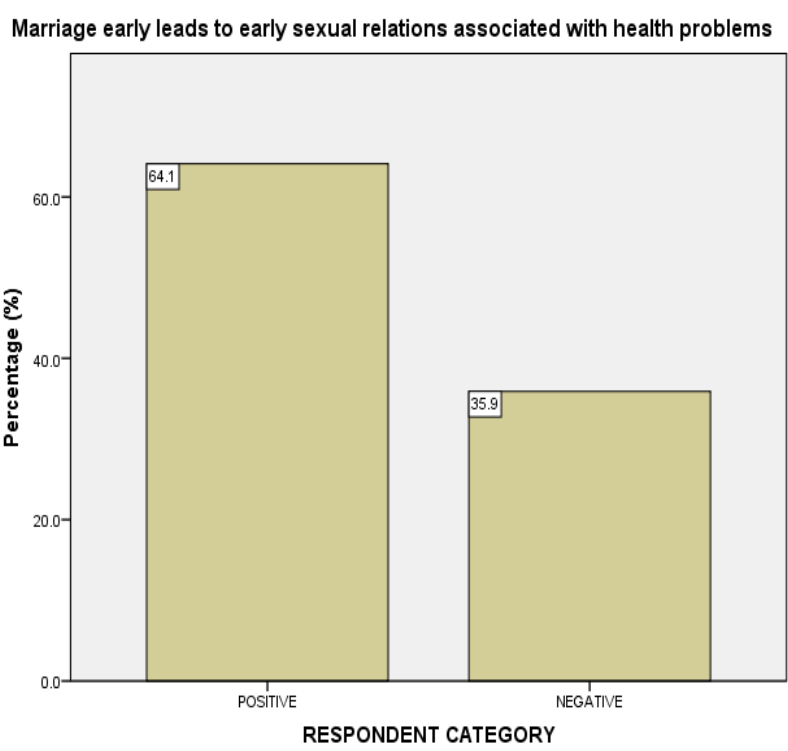

Around $35 \%$ of these girls do not feel that early marriage leads to early sexual debut. Maybe, this could be because marriage or no marriage, young people (boys and girls) are engaging in sexual relationships as some researchers have alluded. 


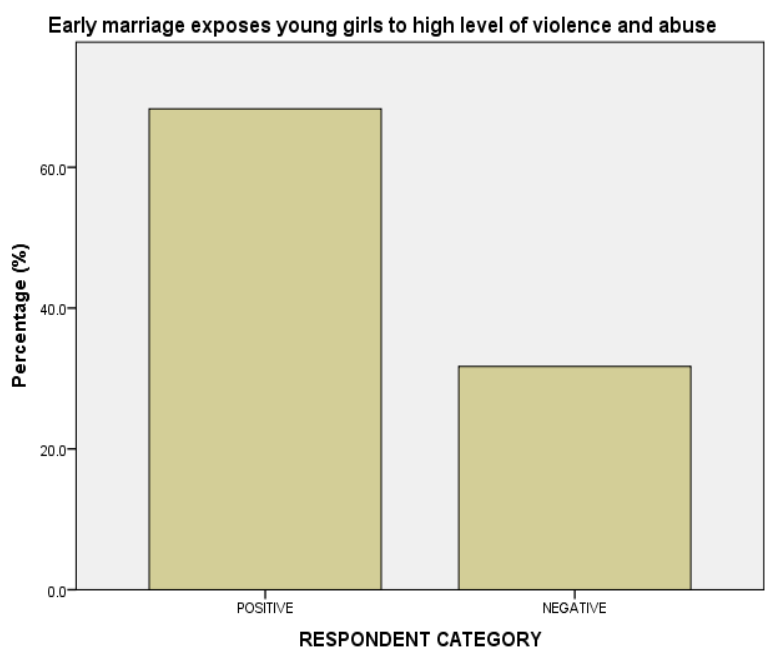

Sixty eight percent $(68 \%)$ of these in-school girls felt that early/child marriage exposes the young bride to high level of violence and abuse. This is so true for the Igbo society because the man having paid bride prize (dowry) on the girl's head now feels that the young bride is his property to deal with and handle as he likes and wishes.

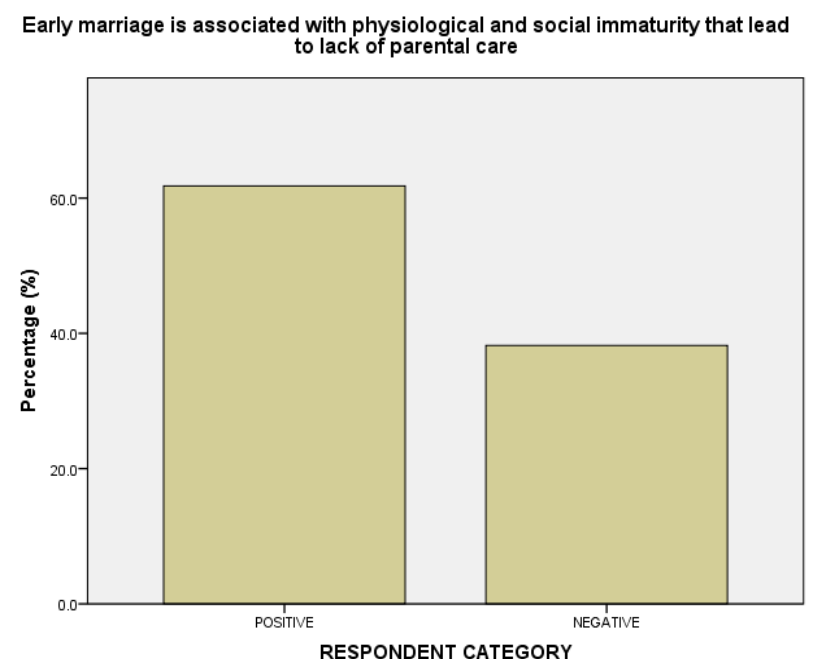

On early marriage being associated with social immaturity leading to lack of adequate parental care for the new born $38 \%$ of the girls do not feel so. This could be as a result of the fact that once a married young girl gets pregnant, her mother or any other female adult relative will be at hand to help and guide her during the last trimester of pregnancy and after delivery - it's called “Omugwo in Igbo culture.

\section{See appendix for the composite chart.}

\section{CONCLUSION}

Early child marriages occur across the different ethnicities, cultures and religions in Nigeria. This harmful traditional practice is rooted in gender inequality and in the low value accorded to girls and is exacerbated by poverty, insecurity and conflicts. It denies girls their rights, choice and participation. Thereby, hindering progress towards a more equal and prosperous nation. Hopefully, with the enactment of the Child Rights Act and the National Strategy to end early marriages, Nigeria will be a society without early/child marriage where girls enjoy equal status with boys and are able to achieve their full potential in all aspects of their lives.

\section{RECOMMENDATIONS}

Based on the findings of this study, the following recommendations were made:

- Girls should have access to quality education since it has been established that girls with secondary school education are less likely to marry early compared with girls with little or no education.

- Both International and National Non - Governmental Organizations. NGOs should step up awareness campaigns on the negative impacts of early child marriage on the child bride, community and society as a whole.

- Increase the use of social platforms and the media to inform and support norm change to end child marriage.

- Nigeria (National) laws should truly reflect international and regional human rights standards.

- Passing anti - early / child marriage laws and policies is to be welcomed but these laws have to be energized and ultimately enforced to create a meaningful deterrent for those who dare to engage in early child marriages. 


\section{APPENDIX}

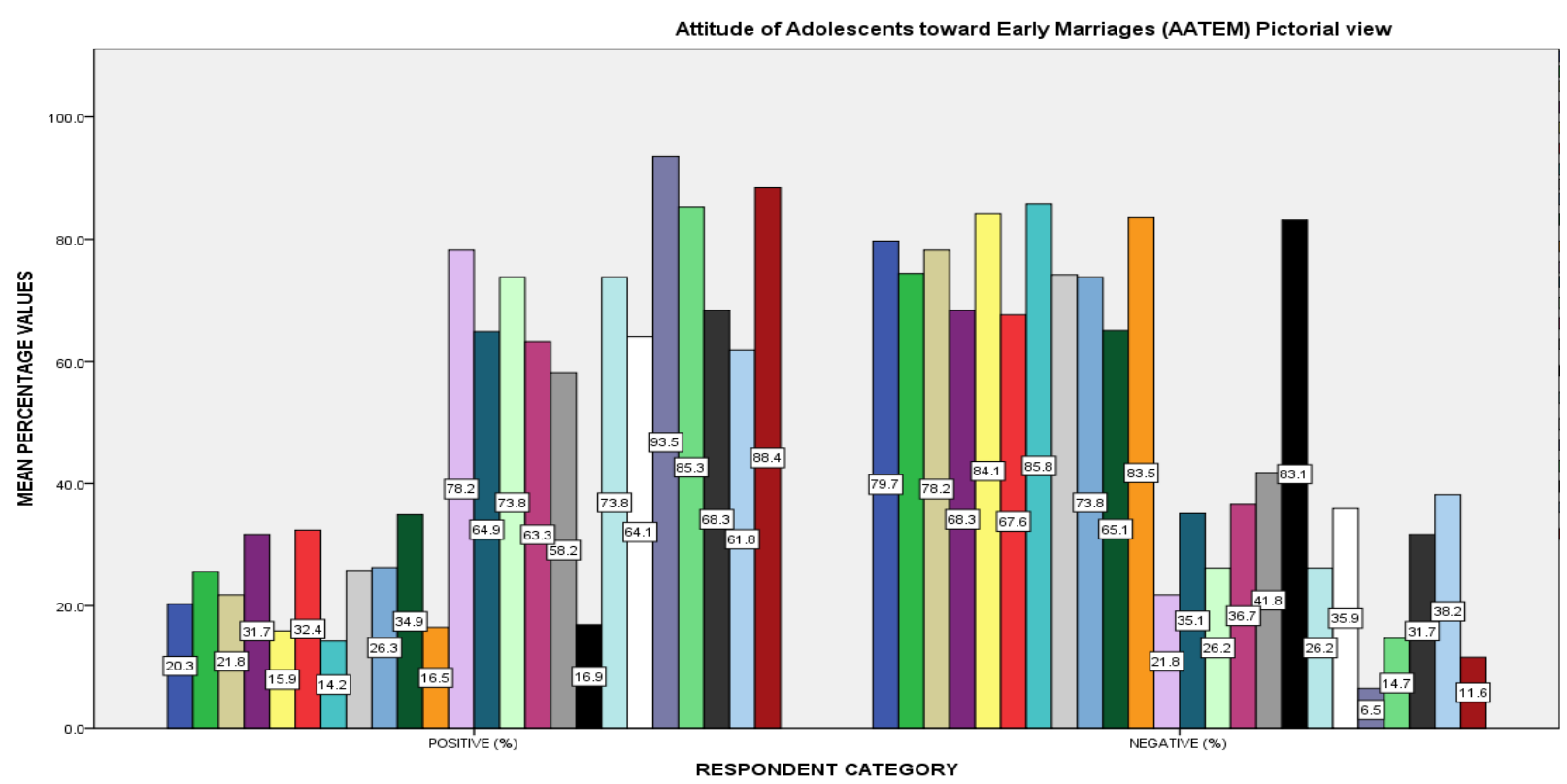

\section{LEGEND}

Early marriage will make my parents happy

Parents should disown their girls who refuse to marry early

Marriage before 18 years is very good

Early marriage is good because the older a girl, the less likely her chances for marriage

Early marriage will enable me prove my fertility

Early marriage is good because my friends and age mates are also getting married at that age

Early marriage enables one to bear legitimate children

Girls marry early to shield them from pre-marital sex

Early helps to prevent unwanted pregnancy

Getting married early enables one to live and train children when young and strong

Early Marriage is good because of the value placed on virginity and so called protection of female child

Early Marriage leads to large number of girls dropping out of school

Early marriage diminishes womanhood

Early marriage has considerable negative implication for social development of young girls

Early marriage leads to low educational attainment

Early marriage denied young girls the ability to make informed decisions about sexual relations

The prevailing old tradition of early marriage where wives are treated as a mere personal property should

Early marriage leads to early pregnancy which can result to mental mortality and infant mortality

$\square$ Marriage early leads to early sexual relations associated with health problems

Early marriage leads to vesico vaginal fistula VVF

Early marriage denies the girls, the ability to make informed decisions about family planning, her health

Early marriage exposes young girls to high level of violence and abuse

Early marriage is associated with physiological and social immaturity that lead to lack of parental care

The traditional practice where a girl child is married off to a suitor at birth should be stopped 
Nnabueze, U. C. (2019). Paradox Of Identities, Girls As Wives, Boys As Children: The Attitude Of In-School Female Adolescents In Enugu State Towards Early Marriages In Nigeria. Advances in Social Sciences Research Journal, 6(5) 348-363.

\section{References}

Adebambo A.V. (2010). Cultural influence on child marriage: Focus on Northern Nigerians Resident in Ogun State, Nigeria. African Journal of Gender and Development 20(2)

Adekola, P.O, Akanbi, M.A, \& Olawalw- Isaac, A. (2016). A qualitative Assessment of the Effects of Child Marriage on Female Education and Entrepreneurship of North-Eastern Nigeria. International Journal of Scientific Research in Multidisciplinary Studies 2 (1). Retrieved 6 ${ }^{\text {th }}$ December 2018 www.isroset.org

Akpala, S.A. (2003). Women's Rights are Human Rights. Enugu: SNAAP Press Ltd.

Annabel, S.E \& Mario, B. (2007). The Experience of Married Adolescent Girls in Northern Nigeria. Population Council of Nigeria Inc. Retrieved Online $20^{\text {th }}$ November, 2018. www.population council .org/pdf/Nigeria Married Ado/pdf

Blealsoe, C.H \& Cohen, B. (1999). Social dynamics of adolescent fertility in sub-Saharan Africa. Washington D.C: National Academy of Science Press.

Centre for Reproductive Law and Policy, CRLP (2011). Women of the World: Laws and Policies Affecting their Reproductive Lives: (Anglophone Africa). New York: CRLP

Chukwukere, G. (1998). The importance of Gender Issues in Nation Building Impact F.S.P Newsletter 53-55

Federal Ministry of Women Affairs \& Development (2016) National Strategy to end Child Marriage in Nigeria. https://www.girlsnotbrides.org/resource-centre/nationa-strategy-end-chld marriage-nigeria 2016-2021/

Federal Republic of Nigeria (1999). Nigerian Constitution Section 42(1)

https://thenationonlineng.net/curtailing-prevalence-girl-child-marraige-nigeria(nd)

International Center for Research on Women, ICRW (2007). How to end Child Marriage: Action strategies for prevention and protection. Washington D.C: ICRW 1-5.

Kwari, M. (2011). Insights into Early Marriage and Girls' Education in Northern Nigeria. Lagos: Action Health Incorporated, AHI

Mbagwu, F.O. (2009). Assessment of the Harmful Cultural Practices affecting the health of rural Women: A study of community based Women Organization in Ebonyi State. A Ph.D submitted to the Department of Adult Education and Extra-Mural Studies, University of Nigeria Nsukka (UNN).

Naija.com>legit (2018). Child Marriage (Online database) https://www.legit.ng/1208962-outrage-70-year-manniger-state-marries underage girl.html? utm_source_Mail fire \& utm

Nour, N.M. (2009). Child Marriage a silent health and human rights Issue. Reviews in Obstetrics and Gynecology 2(1)51-56.

Obianyo, N (2000). Harmful Traditional Practices that affect the well-being of Women. Impact FSP Newsletter 61

Obiweluozo, C.O. (2018). Attitude of Senior Secondary School Students towards Early Marriage and Preventive Measures in Njikoka Local Government Area, Anambra State, Nigeria. An unpublished Project presented to the Department of Human Kinetics and Health Education, University of Nigeria Nsukka, UNN.

Okafor U (2014). The practice of child marriage in Nigeria.

https://www.buffing tonpost.com/udoka-okafor/the practice-of child-Mar_ 6 _ 5133881.html

Onyido, J.A. \& Brambaifa, A.P (2018). Girl-child Marriage in the Nigerian Society, Causes, Impacts and Mitigating Strategies. World Journal of Social Sciences and Humanities 4(2) 104-110

Population Council (2014). Child Marriage Briefing. New York: Population Council.

UNFPA (2013). Every Women, Every Girl/Girls not Brides. Joint News release. New York: UN Foundation/UNFPA/UNICEF/UN Women/WHO/World Vision/World YWCA

UNFPA/UNICEF (2017). Annual Report for the Global Programme to Accelerate Action to end Child Marriage. https://www.unfpa.org/publications/country profiles. Retrieved on 9th December 2018.

UN (2014). The 2030 Agenda for Sustainable Development https://www.sustainabledevelopment.un.org

UNICEF (2013). Girls today, Women tomorrow. New York: UNICEF

UNICEF (22nd October, 2014). Child Marriage.

WHO (2013). Child Marriage.

https://www.who.int/mediacentre/news/release/2013/child_marraige_20130307/en/ 


\section{AUTHOR'S PROFILE}

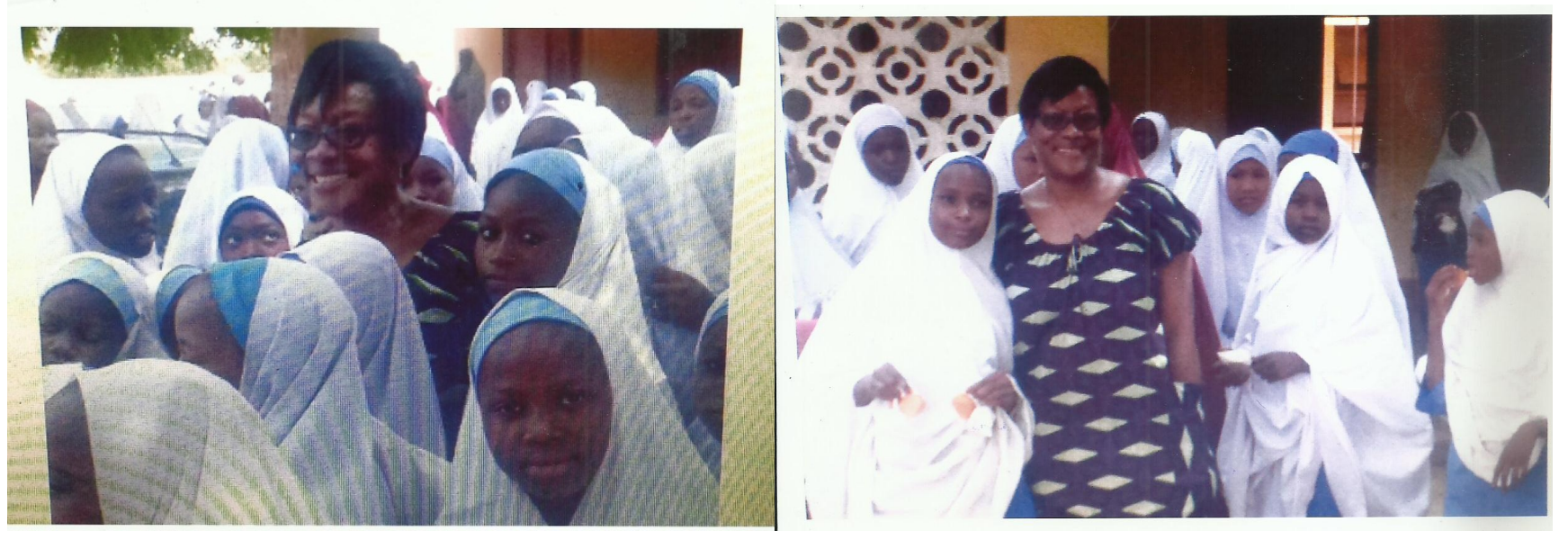

Nnabueze,Ursula Chigozie.

She is a Professor of Public Health Education,

Faculty of Education,

Enugu State University of Science \& Technology, Nigeria.

P.O. Box 4230 Enugu, Nigeria.

Currently, a Visiting Professor,

Department of Public Health,

Faculty of Health Sciences,

Madonna University Nigeria, Elele Campus.

Contact details: nna bueze@yahoo.com

Mobile Phone: +2347031234214

2348171610948 